\title{
LA REVOLUCIÓN MEXICANA Y LA HISTORIOGRAFÍA DE LAS REVOLUCIONES
}

\author{
Iván Jaksić \\ Stanford University \\ Alan Knight \\ Oxford University
}

\begin{abstract}
Resumen: El proceso revolucionario que se desató en México a partir de 1910 plantea una serie de interrogantes al historiador y al cientista social. En una conversación con Iván Jaksić, el destacado profesor de historia latinoamericana de la Uni-
\end{abstract}

IVÁN JAKSIĆ. Doctor en Historia, State University of New York. Académico del Departamento de Culturas Ibéricas y Latinoamericanas y Director del Bing Overseas Studies Program en Santiago de la Universidad de Stanford. Dirección electrónica: ijaksic@stanford.edu.

Alan Knight. D. Phil. en Historia, St Antony's College, Oxford University. Profesor de historia de América Latina, Universidad de Oxford.

* La conversación entre los profesores Iván Jaksic y Alan Knight se dio en el marco de la visita del segundo a la Universidad Adolfo Ibáñez en septiembre de 2012, con ocasión de la inauguración del Centro de Estudios de Historia Política de esa casa de estudios. El profesor Knight dictó a su vez, durante esa visita, la clase magistral "El Estado en América Latina desde la Independencia".

La transcripción de la conversación y la preparación de las notas al pie de página corrió por cuenta de Josefina Araos. 
versidad de Oxford, Alan Knight, discutió sobre las implicaciones metodológicas de su importante estudio monográfico sobre la Revolución Mexicana tanto para la comprensión de los procesos revolucionarios como para la historia comparativa. Entre los temas discutidos se encuentran el rol del Estado, la relación entre el Estado y las regiones, la distinción entre revolución y guerra civil, los legados de la Revolución Mexicana, el papel de Estados Unidos y otras potencias, el uso de "conceptos organizadores" en los estudios históricos, y la situación actual del Estado mexicano. En respuesta las preguntas de la audiencia, Alan Knight desarrolló los puntos anteriores y explicó sus perspectivas sobre el populismo y el nacionalismo en América Latina.

Palabras clave: Revolución Mexicana, historiografía, revoluciones, guerras civiles, Estado nacional, regiones, historia local.

\section{THE MEXICAN REVOLUTION AND THE HISTORIOGRAPHY OF REVOLUTIONS}

Abstract: The Mexican revolutionary process unleashed in 1910 presents a number of challenges to the historian and the social scientist. In his conversation with Iván Jaksic', Oxford University historian Alan Knight discussed many of the methodological implications of his landmark study of the Mexican Revolution for the understanding of revolutionary processes more generally, and for comparative history in particular. Some of the subjects discussed include the role of the state, the relationship between the state and the regions, the distinction between revolution and civil war, the legacies of the Mexican Revolution, the role of the United States and other powers, the need for "organizing concepts" in historical studies, and the current situation of the Mexican state. In response to questions from the audience, Alan Knight expanded on some of these points and offered his perspectives on populism and nationalism in Latin America.

Keywords: Mexican Revolution, historiography, revolutions, civil wars, nation state, regions, local history. 
Iván Jaksić (IJ): La idea en esta conversación es que yo los invite a realizar preguntas a Alan Knight. Pero antes de hacer una serie de preguntas quiero referirme brevemente a la obra de nuestro invitado. Obviamente, Alan es muy conocido por su libro La Revolución Mexicana, realmente una obra magistral, que no ha sido superada después de 25 años. Fue publicada en 1986, con una traducción del Fondo de Cultura Económica en $2010^{1}$. Pero también conviene recordar que es autor de varios otros libros, empezando por su tesis doctoral del año 1974, que trató sobre nacionalismo y xenofobia, centrada más que nada en los extranjeros, e intereses vinculados a ellos, que observaron la Revolución Mexicana. Estudioso también de las relaciones entre México y Estados Unidos, publicó en 1992 un libro que estudia la industria petrolera mexicana, al que se suman una infinidad de otros libros en coautoría $^{2}$. Lo más reciente, y que seguimos esperando todos, es la gran obra de síntesis de la Historia de México, de la que ya han salido dos tomos, mientras varios seguimos insistiendo que empiece con el tercero, que ya es cosa de sentarse a escribirlo ${ }^{3}$. Les recomiendo mucho esta obra, que es realmente un ejercicio de síntesis de primera línea, en donde es posible entender la impronta historiográfica de Alan Knight.

Hay tres elementos que quiero enfatizar de la obra de Alan, y después procederé a plantear algunas interrogantes. En primer lugar, quiero destacar el hecho de que no se puede encasillar su obra dentro de ninguna etiqueta. No es historia económica, no es historia cultural - sobre todo si entendemos por cultural la historia posmoderna-, ni tampoco es historia cuantitativa. Su enfoque central, diría yo, es la historia política, pero una historia política en la que concurren una serie de disciplinas. En particular, Alan es una persona que respeta mucho el

${ }^{1}$ La primera edición fue en inglés, Alan Knight, The Mexican Revolution (Cambridge: Cambridge University Press, 1986 (2 vol.)). La traducción al español del FCE se titula La Revolución Mexicana (México D.F.: Fondo de Cultura Económica, 2010). Sin embargo, la primera traducción corresponde a la Editorial Grijalbo, en 1996.

${ }^{2} \mathrm{Su}$ tesis doctoral fue publicada en Oxford en 1974, con el título $\mathrm{Na}$ tionalism, Xenophobia and Revolution: The Place of Foreigners and Foreign Interests in México, 1910-1915. El texto sobre las relaciones entre México y Estados Unidos corresponde a U.S.-Mexican Relations, 1910-1940: An Interpretation, libro editado por la University of California en 1987.

${ }^{3}$ El profesor Jaksić se refiere aquí a los dos volúmenes de México: From the Beginning to the Spanish Conquest y México: The Colonial Era (New York: Cambridge University Press, 2002). 
campo de la antropología; sin caer en la pomposidad literaria, le gusta mucho escribir bien, le importa que su narrativa sea fluida. Su enfoque es, por lo tanto, absolutamente interdisciplinario, con gran piedad por el lector, para ser así entendible. Sin embargo, ha tenido que entrar en una serie de controversias. La más famosa se inició cuando Stephen Haber escribió un artículo para Historia Mexicana, que produjo una serie de reacciones, que se tradujeron luego, en el año 1999, en un número especial del Hispanic American Historical Review ${ }^{4}$. En este número, Alan no tomó ninguna posición en particular, y es que no quiso abanderarse con ninguna. No le interesa la historia que se aferra a lo cuantitativo - lo que representa en alguna medida la obra de Haber-, ni mucho menos una historia que no sea empírica, y que tenga un grado tan alto de subjetividad. No obstante, entró a la palestra cuando se publicó en 2001 el libro de Eric Van Young, La Otra Rebelión, que fue traducido por el Fondo de Cultura Económica en $2006^{5}$. Yo creo que el destino de Alan y Eric va a ser estar siempre unidos en las estanterías, a propósito de México y sus revoluciones.

El segundo punto que me gustaría enfatizar es algo que lo distingue de otros estudiosos, que es la ausencia de lo que podría llamarse "Estadocentrismo", o lo que él también denomina "Estadolatría", es de-

${ }^{4}$ La controversia a la que el profesor Jaksić se refiere se inicia en 1997 , cuando en la revista Estudios Mexicanos Stephen Haber manifiesta sus temores frente a una Nueva Historia Cultural que cuestionaba los fundamentos básicos de la disciplina histórica. En "The Worst of Both Worlds: The New Cultural History of Mexico", en Mexican Studies/Estudios Mexicanos, 13:2 (verano 1997), pp. 363-383. Luego, en 1999, la Hispanic American Historical Review reunió a un conjunto de historiadores en un número especial que buscaba discutir los límites y alcances de esa Nueva Historia Cultural que ya acumulaba una serie de trabajos historiográficos de gran influencia, entre los que publicaron Haber y Eric Van Young, The Hispanic American Historical Review, 79:2 (1999). Alan Knight se unió a este debate respecto de la Nueva Historia Cultural en 2004, cuando reseñó el libro de Van Young, The Other Rebellion, entrando en una discusión con el autor donde ponía de manifiesto una postura crítica, aunque no completamente distanciada, de esta tendencia historiográfica. Su pertenencia a una escuela diferente, originaria de Inglaterra, quizás permitió en parte la elaboración de una mirada más autónoma sobre esta corriente. En "Eric Van Young, The Other Rebellion y la Historiografía Mexicana", en Historia Mexicana, Vol. 54, No 2 (214) (oct.-dic. 2004), p. 445-515.

${ }^{5}$ Eric Van Young, La Otra Rebelión. La Lucha por la Independencia de México, 1810-1821 (México: FCE, 2006). 
cir, hacer del Estado un deus ex machina ${ }^{6}$. Para Alan Knight, toda la política, en último término, es política local, y por eso es que su narración, sobre todo en la historia de La Revolución Mexicana, es tan matizada. $\mathrm{Y}$ es así que entendemos la revolución como algo mucho más complejo, con motivaciones diversas y actores diferentes. La política de los sonorenses no era la misma que la de los agraristas de Morelos. De esta forma, en su análisis local, Knight logra entregar un cuadro, un mosaico que respeta la especificidad de cada caso, pero al mismo tiempo logra dar una visión de conjunto de lo que fue la historia de la Revolución Mexicana. Este estilo de hacer historia se sostiene, además, en un gran cuerpo de fuentes primarias, que construye y ordena una narrativa que a uno lo transporta al lugar de los hechos.

En tercer lugar, es preciso subrayar el elemento comparativo que caracteriza la obra de Alan Knight. Si bien hace historia de México, sus escritos están repletos de referencias a otras eras y otras experiencias. Por ejemplo, sin desconocer la originalidad de los aztecas, Knight los pone en relación con el Imperio Español, en un ejercicio que le permite reconocer el uso de tácticas imperiales análogas; en otro caso, cuando se trata de examinar el régimen borbónico, afirma claramente que es un régimen centralista y absolutista, que sin embargo tiene también elementos feudales, mezcla que se repite en otras monarquías europeas del período. La Revolución Mexicana, por su parte, también puede ser una revolución única, pero es una revolución que, para poder comprenderla en su cabalidad, debe ser comparada con otras revoluciones. Particularmente la boliviana de 1952 y la cubana de 1959. Sin embargo, aun así, Alan Knight no las pone todas en un mismo grupo. Para analizarlas en su complejidad, introduce nuevamente una distinción entre las revoluciones burguesas y las revoluciones socialistas, cuestión que permite clasificarlas en categorías que hacen posible el reconocimiento de su heterogeneidad. También, por ejemplo, compara diferentes personajes clave, como Francisco Madero, Alexander Kerenski, Salvador Allende y otros, reuniéndolos a todos en el mismo concepto, al momento de intentar identificar los compromisos, los límites, a los que llegan en diferentes revoluciones políticas. Lo que une a todos estos

${ }^{6}$ A lo largo del texto se ocupará la palabra "Estado" con mayúscula cuando se hagan referencias relativas a Estados nacionales o al Estado como categoría analítica. En el caso de los estados federales se utilizará, en cambio, la palabra "estado". 
casos comparativos, de pronto, es alguna referencia literaria, como a La Ilíada, o a ciertos personajes novelescos; en el fondo, Alan Knight busca darnos una imagen de México que evidencia el hecho de que, para comprenderlo, no debe afirmarse su excepcionalidad, sino analizarse desde su contexto regional y mundial, sin nunca negar su propia particularidad.

Dicho lo anterior quiero iniciar las preguntas a Alan Knight. La primera es a propósito de la historia nacional, esto es, cómo equilibra lo que sería una historia de México con la historia local, y la duda que uno tiene siempre respecto de esta combinación, o de este equilibrio. ¿Es que a veces los árboles no dejan ver el bosque?

Alan Knight (AK): Es cierto que en los últimos años, especialmente en la historia de México - aunque también en la de otros países-, ha habido un gran énfasis en la historia no solamente regional sino local. De ahí que se han identificado, en total, al menos tres niveles de análisis: nacional, regional y local. Es de ahí que han surgido muchos estudios de gran calidad, siendo justamente la historia regional y local la tendencia más fértil en los últimos años. Es lo que Luis González llamó también "microhistoria", con la que comenzó toda una ola de investigación de los municipios ${ }^{7}$.

Hay, eso sí, un problema en esto, tal como tú planteas, y es que una acumulación de estudios regionales o locales no nos da necesariamente una imagen más total de un fenómeno nacional. Yo comencé la Revolución Mexicana hace muchos años, habiendo entrado primero al tema por el lado de los intereses extranjeros y las compañías petroleras. En ese momento, por tanto, mi perspectiva de análisis fue nacional. Sin embargo, en una segunda etapa, me di cuenta que para entender la Revolución, que era también un objetivo en mi estudio, había que reconocer otros niveles. Y es que siendo un movimiento nacional fue también muy dinámico, dinamismo entendido en un sentido principalmente doméstico, en que se vuelven relevantes las particularidades de cada lugar. Por lo tanto, para comprender esa Revolución, se volvía necesario conocer también las grandes diferencias entre, por ejemplo, Sonora

7 Alan Knight está haciendo referencia a la obra de Luis González, Pueblo en Vilo: Microhistoria de San José de Gracia (México: El Colegio de México, 1968). 
en el noroeste y Chiapas en el sur, Oaxaca, Morelos, etc. De hecho, en relación con la actualidad, no obstante la centralización de México después de la Revolución, sigue siendo un país bastante heterogéneo. Incluso hoy en día, más que Chile quizás, no se puede entender el país sin entrar en estas cuestiones.

Ahora, el problema es cómo juntar todas las diferencias sin perdernos en una infinidad de pequeñas historias locales. Resolver eso es una cuestión de juicio, de balance. Lo que podemos hacer, por ejemplo, es un poco de historia comparativa, pero en vez de hacerlo entre naciones, que es la norma, puede ser en small group, para el caso de México -y también de Chile_-, comparando regiones en relación con ciertos problemas. Por tanto, entender México es también una forma de historia comparada, porque uno siempre está tratando de balancear la experiencia del norte, del sur, del centro; de diversos lugares, tan diferentes en cuanto a su desarrollo económico, social y político. Aun así, estoy de acuerdo con el riesgo de tender hacia lo que algunos plantean como "saber más y más sobre menos y menos", tendencia que debe resistirse en cierta medida. Una manera de hacerlo es balancear esas historias locales con una perspectiva más amplia, como la nacional, aun cuando hoy día en México muchos piensan que la historia nacional es una forma de diletantismo porque pareciera ser demasiado estratosférico. Lo importante es ir al fondo, y contrastar esos enfoques, como señalé, con perspectivas nacionales e internacionales.

IJ: La segunda pregunta es sobre la teoría de las revoluciones. En el caso de Alan Knight, en su estudio sobre México no comienza directamente hablando de una "revolución", sino que se hace la pregunta de si lo que ocurrió a partir de 1910 puede entenderse con esa categoría. Para ello, revisa la manera en que se ha abordado el concepto, principalmente en la literatura sobre la "teoría de las revoluciones". Y hay una distinción que me llama la atención, y es aquella entre los enfoques descriptivos y los funcionales. A Alan Knight, al parecer, no le interesan - o más bien, no son de su preferencia - los enfoques descriptivos; sin embargo, queda la duda respecto a qué define a cada uno.

AK: Esa distinción entre enfoques descriptivos y funcionales la hice hace varios años en un artículo sobre la Revolución Mexicana y cómo compararla con otras revoluciones. En él sostenía que si 
pensamos en “¿Qué es una Revolución?” nos tendríamos que plantear también la pregunta de por qué llamamos revolución a la Revolución Mexicana. Esto es algo importante al menos en el debate mexicano, porque hay quienes dicen que no fue una revolución. Como no fue suficientemente dinámica, o importante, no cambió la sociedad, entonces no fue una verdadera revolución, al estilo, por ejemplo, de la Revolución Francesa o la Revolución Rusa. En ese juicio se ve que hay un modelo de revolución que varios historiadores han manejado, y que tiene ver con los criterios necesarios - no la esencia, no me gustan las esencias - para que la Revolución Mexicana, o cualquier otra, llegue ser parte de un grupo bastante reducido en la historia. Sabemos, por ejemplo, que hay una primera distinción, muy antigua y común, que es aquella entre rebeliones, cuartelazos, golpes y revoluciones. El problema entonces no es la distinción misma sino cómo hacerla, cómo establecerla.

Por el lado descriptivo, mi intención era mostrar cómo en México, y en otros casos, se ve un proceso de conflicto político, social y militar desde dos lados, que implica una movilización, incluso una movilización popular — quizás por ambos lados, quizás por un lado más que otro-, en búsqueda de ciertos objetivos que polarizan a la sociedad. Y es que hay cuestiones muy importantes en juego cuando se desencadena una revolución. Parece obvio, pero hay que entender eso como un proceso de lucha, lo que Charles Tilly llama una "situación de soberanía múltiple", cuando hay facciones y grupos en conflicto, donde muchas revoluciones son aplastadas al principio, y sólo cuando una de ellas progresa o llega a su fin es entonces posible entrar al aspecto más funcional, que tiene que ver con el resultado: qué alcanzó, qué hizo, finalmente, la revolución. Aparece ahí otro debate, para el caso de México, respecto de si fue una revolución exitosa al menos en el sentido muy sencillo de que los revolucionarios ganaron, no fueron aplastados, y cuando llegaron al poder la contrarrevolución fue derrotada. Ahora, la pregunta que emerge ahí, en ese momento, es la de qué hicieron una vez instalados en el poder, que para mí es un problema de mayor duración y que avanza a lo largo de los años veinte y treinta, más o menos hasta el gobierno de Lázaro Cárdenas. Es entonces la pregunta por lo que se hizo, por la función o resultado de la revolución en el cambio efectivo de la sociedad, el Estado, o cualquier otro aspecto. 
Obviamente esto es difícil de calibrar, de medir con precisión, pero creo que se puede llegar a la conclusión, en el caso de México y otros, que el nivel de cambio fue sustancial y estructural, aun cuando no hubo una transformación en el modo de producción, ya fuera capitalista, socialista o feudal - el capitalista es un cambio que se ve muy raramente y ha sido prometido en algunos pocos casos, específicamente en el de revoluciones socialistas, como la china y la cubana-. Y es que en muchas revoluciones, la de Bolivia, la Francesa y la de México, a pesar de que no existió esa transformación, sí hubo una modificación significativa, que cambió de manera definitiva la relación Estadosociedad. Eso, me parece, es lo que hace válido llamar a estos procesos como revoluciones. Cosa que no se puede decir en el caso de muchas otras rebeliones, de manera que intento mantener la distinción entre golpes, cuartelazos, rebeliones y revoluciones grandes, que son sociales, políticas, etc. Y esta es mi manera de conceptualizarlo con un poco más de detalle. Con todo, León Trotsky y otros han planteado que sí hay leyes que permiten clasificar las revoluciones, en la medida en que obedecen a una trayectoria común; sin embargo, yo creo que cada una es diferente ${ }^{8}$.

IJ: Siempre dentro del aspecto conceptual, es evidente en tu trabajo que rechazas las generalizaciones que son demasiado abarcadoras, pero también el abandono de algún tipo de generalización que ayude a ordenar. En relación con eso, tú prefieres hablar de organizing concepts, como de teorías que se pueden utilizar muy provisoriamente. Pero ¿qué significan estos organizing concepts?

AK: Creo que todo historiador utiliza organizing concepts. La cuestión es cuáles son y si son bien definidos. Hay historiadores, como el caso de algunos de mis profesores, que negaban absolutamente cualquier conceptualización, eran netamente experiencistas y, sin embargo, hablaban todavía de la "Monarquía", el "Estado", categorías que son conceptos que hay que aclarar, ya que no es necesariamente evidente lo que ellos quieren decir. Entonces mi idea es que, en primer lugar, se deben definir los conceptos. Por ejemplo, en relación con lo que hemos

${ }^{8}$ León Trotsky desarrolló su perspectiva en el libro titulado La Revolución Permanente, publicado en 1930. 
venido hablando: qué entendemos por una revolución. No tiene por qué ser algo demasiado largo, que ocupe páginas y capítulos, lo que se volvería algo aburrido, pero sí explicar qué se está estudiando. En segundo lugar, pienso que se pueden plantear lo que yo llamo "hipótesis de mediano rango", que vienen a ser una suerte de respuesta a las grandes teorías como la "modernización" o el marxismo, que en la década de 1960, cuando yo estudiaba, estaban muy de moda. Creo que esas teorías son muy sencillas, a veces dogmáticas, donde todo debe cuadrar dentro de un esquema demasiado rígido. En el lado contrario están los historiadores que mencionaba antes, y que no quieren arriesgar ninguna comparación, ninguna hipótesis causal para explicar por qué pasan las cosas. En medio de ambos es que planteo el establecimiento de ciertas hipótesis de mediano rango. Por ejemplo, para el caso de la Revolución Mexicana, hablar de una "revolución burguesa" es realmente un poco estratosférico, y quizás es mucho mejor preguntarse: por qué hubo un movimiento revolucionario tan fuerte en el estado de Morelos, provocado por el zapatismo, mientras que en Oaxaca, que no estaba tan lejos, fue bastante pacífico, donde incluso los movimientos populares fueron, en ocasiones, muy reaccionarios. Se establece así una comparación donde se pueden generar estas hipótesis de mediano rango sobre, por ejemplo, la naturaleza de la movilización popular y campesina, la naturaleza del Estado, los caciquismos, etc.

En este sentido, pensando en la historia de la Revolución, en la historiografía de la Revolución - y quizás otros problemas, como la historia de Chile_- en este nivel se ve un mejoramiento. Hay una cierta acumulación en la historiografía de debate y conocimiento histórico, que tiene que ver, más que nada, no con una gran línea teórica que lo explica todo - tampoco con pequeñeces que pueden ser interesantes pero meramente idiosincráticas-, sino más bien con la formulación y discusión de hipótesis de mediano rango. Es un poco al estilo de Alan Heston en relación con la economía de América Latina, en que a veces estudiando problemas limitados puedes decir cosas interesantes, sugerentes y útiles sin tratar de hablar sobre grandes teorías dogmáticas 9 .

${ }^{9}$ Alan Heston es conocido por sus investigaciones económicas en conjunto con Robert Summers en la Universidad de Pennsylvania, donde dirigen el Center for International Comparisons (CIC). 
IJ: Esto último es evidente en la obra de Alan Knight, a diferencia de la mayoría de las tesis doctorales o libros donde uno encuentra el marco teórico ocupando un lugar preponderante. Eso no se puede esperar de Alan Knight. Sí, en cambio, algunos momentos o pausas en que aparecen referencias a ciertas teorías y a ciertos autores, algunos con mucha recurrencia. Su obra, por ejemplo, frecuentemente remite a Max Weber, a Perry Anderson y en muchas ocasiones también a Barrington Moore. En cambio, uno echa de menos a Jean Francois Lyotard, Jacques Derrida o Michel Foucault. ¿Qué quiere decir esto? ¿Significa que la historia debe ser, o tú en particular tienes una mayor preferencia por, una historia más relacionada con las ciencias sociales?

AK: Para mí Lyotard es un traje de baile o de gimnasio, no conozco nada de él. A Derrida y Foucault los he tratado poco también. Ahora, me parece que Foucault sí dice algunas cosas interesantes, aunque yo no soy un experto, no soy foucaultiano como tú bien sugieres, y en parte quizás tiene que ver con la formación intelectual y con mi generación. Comencé antes de que Foucault se pusiera de moda. Eso no quiere decir que uno no pueda aprender cosas nuevas, pero creo que la preferencia por un autor u otro depende, en parte, de lo que parece útil en cuanto a los problemas que estás estudiando. En mi caso, más que nada, era la Revolución Mexicana, y en relación con eso Max Weber siempre me llamó la atención como teórico del Estado. Marx también; he leído bastantes libros acerca de Marx que me han ayudado, pero creo que Weber, por su análisis de las formas de autoridad y las formas del Estado, siempre es muy sugerente. Por otro lado, el libro de Barrington Moore fue muy conocido cuando yo era estudiante, en parte por su estructura de historia comparativa, muy ambiciosa, donde tomaba cerca de ocho países para analizar la relación entre terratenientes y campesinos, la formación del Estado, la agricultura, entre otras cosas. Quizás no fue un modelo totalmente exitoso, pero sí un buen ejemplo de cómo armar una historia comparativa que mezclara, además, historia, sociología, ciencia política, etcétera ${ }^{10}$.

${ }^{10}$ El texto emblemático de Weber sobre el tema del Estado y la teoría de la dominación corresponde a Economía y Sociedad: Esbozo de Sociología Comprensiva (México: FCE, 1964). El de Barrington Moore se titula Los Orígenes Sociales de la Dictadura y la Democracia: Señor y Campesino en la Formación del Mundo Moderno (Barcelona: Ediciones Península, 1973), la primera edición en inglés es de 1966. 
No sé si queremos entrar en la cuestión espinosa del posmodernismo. Foucault, Derrida y Lyotard nos llevan en esta dirección. No es que esté en contra de esta línea; hay ejemplos de la Nueva Historia Cultural, que han sido influenciados por el posmodernismo, que me parecen útiles, interesantes y novedosos. Sin embargo, el posmodernismo en su forma más intransigente y más extrema no es para mí el enfoque adecuado o la manera correcta para estudiar y hacer historia.

IJ: Volviendo al tema de las grandes teorías, quisiera hablar ahora sobre Alexis de Tocqueville, especialmente en relación con su obra El Antiguo Régimen y la Revolución ${ }^{11}$. En el libro sobre la Revolución Mexicana tú haces referencia a lo que llamas una conclusión "ultratocquevilliana", en el sentido de que nada cambia, o que, si lo hace, es para permanecer igual. No obstante, al mismo tiempo, es bastante obvio que tienes algunas simpatías por Tocqueville; me parece que lo utilizas en varias ocasiones, como cuando planteas que la Revolución y sus transformaciones no pueden entenderse sin el Porfiriato. De modo que quisiera que nos contaras cuál es el equilibrio entre lo "ultra-tocquevilliano" y lo legítimamente tocquevilliano.

AK: No soy experto en Tocqueville; hay gente aquí que conoce más que yo y tiene opiniones fuertes sobre Tocqueville, de manera que hay que ir muy cuidadosamente en este tema. Es cierto que hice referencias a Tocqueville y su contribución, que tiene que ver con la Revolución y el ancien régime, y no con la cuestión de Estados Unidos. Es la idea de que la revolución, inicialmente, destruye el Estado, el antiguo régimen, para después construir un régimen y un Estado más fuertes. La cita de "las cosas tienen que cambiar para que queden iguales" no es exactamente de Tocqueville sino de Giuseppe Tomasi di Lampedusa, de la novela El Gatopardo, que se vuelve muy frecuente en los estudios mexicanos, no tanto sobre la Revolución — porque creo que no sería muy apropiado - como sobre el Partido Revolucionario Institucional (PRI) en sus últimas décadas. La idea de que el PRI siempre estaba introduciendo nuevas reformas, no para cambiar las cosas sino para

${ }^{11}$ Anotamos la referencia completa: Alexis de Tocqueville, El Antiguo Régimen y la Revolución (Madrid: Alianza, 1982), la primera edición es de 1856. 
mantener su hegemonía. A fin de cuentas no tuvo éxito, pero la cita "lampedusiana" tiene más que ver con el PRI que con la Revolución ${ }^{12}$.

Tocqueville es sugerente en el sentido obvio de que la Revolución destruyó el Porfiriato, y que después de varios años de caos y lucha, destrucción económica, caída demográfica, etc., el Estado pudo reinventarse y restablecer su autoridad. Lo interesante es que se creó un Estado más fuerte que antes; de hecho el Estado revolucionario en los años veinte y treinta tuvo mucha más penetración social. El régimen de Porfirio Díaz parecía muy fuerte y, desde afuera, los comentaristas extranjeros elogiaban constantemente el poder de Díaz, la estabilidad, el gran progreso económico. Sin embargo, fue un Estado que casi no tuvo instituciones: no existían partidos, no había elecciones, no había organizaciones masivas como sindicatos, grupos campesinos, etc. La Revolución, yo diría, no fue un esquema de los propios revolucionarios, sino, más bien, una reacción a la situación concreta de movilización popular de campesinos y obreros donde el Estado, para sobrevivir y fortalecerse, tuvo que reaccionar e incorporar tanto a los obreros como a los campesinos. No fue simplemente una imposición de arriba-abajo, tampoco un movimiento popular simplemente desde abajo, sino un proceso dialéctico entre arriba y abajo. Por tanto lo que emergió, especialmente a fines de los treinta, fue un Estado mucho más fuerte y más firmemente establecido que el anterior.

Así, pues, sí hay un aspecto tocquevilliano; el problema es que algunos historiadores, los ultra-tocquevillianos, han sobreenfatizado esto y se han enfocado en el Estado en sí, perdiendo el hecho fundamental — para mí obvio - de que el Estado no podía hacer su Revolución ni establecerse sin forjar ciertas alianzas o pactos sociales. Por lo tanto, no fue simplemente el Estado imponiéndose desde arriba, sino una relación entre el Estado y la población o la sociedad civil. Incluso con el PRI, si uno lo piensa en las palabras de Vargas Llosa como la "dictadura perfecta", no dejó de tener cierta relación dialéctica entre el Estado y la población. Los poderes, el poder central, el del presidente mismo, no fueron tan grandes como a veces se supone.

12 Referencia completa de la obra a la que alude Knight: Giuseppe Tomasi di Lampedusa, El Gatopardo (Buenos Aires: Losada, 2004), publicada por primera vez en 1958. 
IJ: Hablando de los cambios desde arriba y los cambios desde abajo, Alan Knight hace comparaciones que, por lo general, son horizontales pero también longitudinales en el tiempo. Por ejemplo, los cambios borbónicos y los cambios del Porfiriato. Tú te refieres a ambos como parecidos, en cuanto a que en ambos períodos se intentó modernizar la sociedad desde arriba pero sin modificar las relaciones de producción. Llama la atención este concepto de las "relaciones de producción", porque en varias ocasiones dices que hay que medirlas solamente en el largo plazo. En el caso de México, por ejemplo, en el tránsito del feudalismo al capitalismo, las grandes transformaciones deberían observarse en un horizonte de larga duración. Ahora bien, ¿cuáles serían los parámetros para ver estos cambios en las relaciones de producción?

AK: Es cierto que, pensando en el modelo más o menos marxista, cuando estamos hablando de fuerzas de producción y relaciones de producción, estas normalmente se caracterizan por ser cambios graduales. Quizás hay que repetir la distinción entre las revoluciones burguesas-capitalistas, por un lado, y las socialistas, por otro. Obviamente en los casos de China, Rusia y Cuba hubo una revolución política que después pudo institucionalizar una economía de mando centralizado, socialista o comunista. En ese caso, la revolución sí conllevó un cambio de las relaciones de producción, donde la Cuba socialista fue muy diferente de la Cuba pre-revolucionaria de Batista, sostenida en una lógica capitalista. En el caso de México, de Bolivia, incluso de la Revolución Francesa y la de Inglaterra, hubo también una revolución política - a veces con rasgos sociales - , pero que en cambio no transformó las relaciones de producción.

En México, por ejemplo, lo que vemos es un proceso mucho más largo de transformación del campo donde la Revolución, a mi juicio, fue quizás un motor de aceleración. Durante el Porfiriato existía todavía bastante coacción de la mano de obra - menos que en Guatemala, quizás-, pero todavía en el sur de México había peonaje por deudas junto con una dominación bastante fuerte de terratenientes; no propiamente feudales pero que sí tenían un monopolio casi completo de las tierras, al menos de las mejores. La Revolución, entonces, trajo como resultado la destrucción de esta hegemonía terrateniente oligárquica, con una reforma agraria bastante extensa y radical, en la cual el peonaje por deudas fue, también, más o menos abolido. Entonces si la Revolución cambia a 
México de una sociedad feudal a una sociedad capitalista o con rasgos socialistas, no sé si se podrá responder, porque como dije antes estos son conceptos demasiado estratosféricos para entender el problema. Pero sí hubo un proceso, aunque no me gusta la palabra, de "modernización" de la economía, un cambio en las relaciones de producción en el campo, formando un campesinado mucho más fuerte, con más movilización, con más libertad, y al mismo tiempo un sector obrero con la formación de sindicatos bastante fuertes - como en las compañías de petróleo, ferrocarriles y la minería-. Por lo tanto, creo que la Revolución no transformó todas las relaciones de producción, ya que eso pasa muy raras veces, pero sí las afectó sustancialmente, y por eso es que no fue simplemente una revolución política, sino también tuvo un importante aspecto social y económico.

IJ: Si te puedo llevar un momento al contexto internacional, hay un dicho famoso y jocoso que se le atribuye a Porfirio Díaz, que dice "Pobre México, tan lejos de Dios y tan cerca de Estados Unidos". Sin embargo, cuando uno lee el trabajo de Alan Knight, una de las cosas que más destaca es el hecho de que, al parecer, Estados Unidos no tuvo injerencia en la Revolución. Esto, claramente, no lo generaliza, ya que afirma que el contexto internacional puede ser un importante agente de influencia, como por ejemplo en la Revolución Cubana, que constituye un caso completamente diferente. Pero entonces ¿cómo se explica que Estados Unidos haya tenido tan poco que ver en la Revolución Mexicana?

AK: No diría que no tuvo ninguna injerencia. No obstante, en mi interpretación, la influencia de Estados Unidos en la Revolución, desde sus comienzos con la revolución armada y luego a través de los años veinte y treinta con todas las reformas sociales, ha sido bastante exagerada por otros historiadores. En parte, hay una suerte de alianza entre historiadores o comentaristas mexicanos nacionalistas, que pueden ser de la izquierda o de la derecha - hay de todo-, y por otro lado historiadores norteamericanos, más que nada desde la izquierda, que siempre quieren ver a Estados Unidos como el gran villano del complot. Como John Hart, por ejemplo, que va buscando datos por todos lados para demostrar que Estados Unidos tiene su influencia acá y 
allá $^{13}$. Yo he revisado sus fuentes, y habiendo archivos enormes, con un montón de datos, no es difícil sacar algo del estilo "fulano de tal dice que las compañías petroleras están subvencionando a este caudillo, para derrocar al gobierno", etc., etc. Se pueden construir, en ese sentido, teorías muy bonitas, especialmente en esta área que tiene que ver con conspiraciones y cosas un poco clandestinas, pero que a mi juicio son muy exageradas.

Precisamente, yo comencé mi tesis original estudiando el papel de los intereses extranjeros, de Europa y Estados Unidos, en la Revolución Mexicana. Y llegué a la conclusión, después de varios años de investigar y escribir, que no había sido tan importante, en parte porque la revolución armada en México ocurrió, más o menos, en paralelo con el desarrollo de la Primera Guerra Mundial, cuando todas las grandes potencias tenían otras preocupaciones, principalmente las europeas. Pero también Estados Unidos, que, alrededor de 1916 o 1917, tuvo como una preocupación importante que México se mantuviera relativamente tranquilo, que no fuera un problema ya que el gran conflicto era el que se estaba desplegando en Europa. En una segunda instancia, durante los años treinta, cuando la Revolución Mexicana estaba llegando a su período más radical en términos de reformas sociales, con la reforma agraria y la expropiación petrolera — que involucraba intereses extranjeros muy poderosos - , las grandes potencias —y las compañías petroleras - no hicieron nada. Sí protestaron. Los ingleses, por ejemplo, lo hicieron de una manera tal que los mexicanos rompieron las relaciones con ellos; sin embargo, ese quiebre no afectó la situación mexicana. En un tercer momento, en medio del auge del Eje previo a la Segunda Guerra Mundial, Estados Unidos nuevamente reconoció lo esencial que era mantener buenas relaciones con México. Henry Morgenthau, quien era el Secretario del Tesoro durante esos años, escribió justamente en su diario que las buenas relaciones con México en ese momento eran más importantes que cualquier cantidad de petróleo. Me parece, entonces,

${ }^{13}$ En su libro sobre la Revolución, Alan Knight cita el trabajo de John Hart, Anarchism and the Mexican Working Class, 1869-1931 (Austin: University of Texas Press, 1978). Además, para esta discusión, Knight está haciendo también referencia a los trabajos Empire and Revolution: Americans in Mexico since the Civil War (Berkeley: University of California Press, 2002), y Revolutionary Mexico: The Coming and Process of the Mexican Revolution (Berkeley: University of California Press, 1987). 
que la Revolución Mexicana tuvo la fortuna, en su origen y en su período más radical, de ocurrir justo cuando Estados Unidos, por el contexto internacional, requería - y buscaba - tranquilidad en el vínculo con México, y con las relaciones con el resto de América Latina. Ejemplo de ello fue también la política del "Buen Vecino" liderada por Franklin Roosevelt.

Si uno compara esto con la situación de Guatemala en los cincuenta, en plena Guerra Fría y con una administración republicana en la Casa Blanca, el desarrollo de los hechos y la influencia externa son completamente diferentes. La Revolución Guatemalteca, que en la administración de Jacobo Árbenz tenía algunas similitudes con la de Cárdenas — por ejemplo, respecto a la Reforma Agraria—, fue completamente aplastada, en parte por la CIA, en parte por la oposición guatemalteca. En ese sentido, entonces, el contexto internacional favoreció a los mexicanos en su ensayo radical, constatación que, yo creo, explica en parte por qué la revolución armada mexicana, que fue tan caótica, no pudo ser controlada. Incluso cuando los norteamericanos intervinieron dos veces en Veracruz y luego con la expedición punitiva en el norte, fue un caos total. Involucrarse en las revoluciones de otros países, en cualquier caso, siempre será ocasión de caos, lo que evidencia que realmente no se pueden controlar. Es cierto que, por ejemplo, en los años veinte, cuando el Estado revolucionario mexicano, con los sonorenses, trató de establecerse y mejorar sus finanzas, de atraer inversión, Estados Unidos tenía más influencia en el país, debido a los banqueros, Dwight Morrow y otros. Pero eso no podía impedir una significativa autonomía por parte del Estado mexicano. Entonces, claro, depende un poco de la década, pero si uno toma los tres decenios de la Revolución, México tuvo mucha más autonomía respecto de Estados Unidos que la que tuvo después.

IJ: Tengo una última pregunta antes de pasar a las del público, y está motivada por la visita a Chile del presidente recién electo Enrique Peña Nieto. La pregunta es, ¿él es el retorno del PRI? No sabemos hasta qué punto Enrique Peña Nieto es "nieto" de Álvaro Obregón, de Plutarco Elías Calles, o de Lázaro Cárdenas, ni qué ha pasado en todos estos años. ¿Cómo se explica este cambio en que regresa, finalmente, el PRI? ¿Hay continuidades, hay rupturas? 
AK: Supongo que cada revolución llega a su fin, es decir, no se puede mantener una revolución permanente. Mao Tse Tung hizo el intento de armar nuevas revoluciones, con la Revolución Cultural, por ejemplo, pero no me parece que sea la manera adecuada de gobernar un país. Para el caso de México, entonces, creo que era, no inevitable, pero sí muy probable que, después de toda la ola revolucionaria, viniera una reacción, la que se vio muy claramente, pienso, a comienzos de los años cuarenta. Durante el gobierno de Miguel Alemán, y no es una afirmación muy original, se llevó a cabo un nuevo proyecto de industrialización que acompañó la formación del PRI, que, no obstante su etiqueta de Partido Revolucionario Institucional, fue siendo cada vez más institucional y menos revolucionario. Eso es lo que hace tan difícil ver al México del milagro económico y de la hegemonía del PRI en los años cincuenta, sesenta, setenta, como un régimen o sociedad revolucionaria.

Ahora bien, la Revolución todavía está presente en los libros de texto, en los aniversarios, en las estatuas y en las conmemoraciones. Pero creo que siempre hubo una brecha, y que fue cada vez mayor, entre la retórica y la realidad, y me parece que eso - junto a otros factores obviamente- explica también la transformación del PRI; su retórica no pudo cuadrar bien con la realidad de un México capitalista, que crecía rápidamente, con muchas desigualdades y con una clase capitalista muy fuerte, especialmente en Monterrey. A fines de los 80, con el llamado "giro neoliberal", Carlos Salinas y otros trataron de reformar toda la retórica, el discurso, con el objetivo de presentar al PRI como un partido justamente más neoliberal, reformista, procapitalista, que dio, por ejemplo, la bienvenida al Papa, un hecho sumamente novedoso en la política mexicana, asegurando un éxito que duró varios años. Sin embargo, debido a varias crisis económicas y muchos otros elementos, el PRI, al final de cuentas, no podía llevar a cabo esta re-imaginación o reformulación de su proyecto, lo que se hizo bastante obvio hace dos años, para el Centenario de la Revolución.

Para terminar, entonces, aun cuando la Revolución sigue siendo un punto de referencia muy importante en la historia, en la historiografía y en la cultura, me parece que en términos políticos ya es cosa del pasado. Incluso la izquierda mexicana — al menos la más sensata - no piensa ni quiere regresar a la Revolución. Los llamados "zapatistas", que utilizaron el nombre de Zapata para definirse, tampoco buscaron realmente volver a aplicar la política del plan de Ayala de hacía un 
siglo, porque no podían. Y es que el México de comienzos del siglo XXI es tan diferente del México de la Revolución, que es necesario pensar en nuevas políticas y nuevas estrategias, tanto en la izquierda como en cualquier otro partido.

IJ: Doy cierre entonces a mi ciclo de preguntas, pasando ahora a las que quiera realizar el público.

\section{Conversación CON EL PÚBlico}

Pregunta: Relacionando sus planteamientos respecto de una periodificación de la historia del Estado en América Latina con lo que ha desarrollado ahora, pareciera que estamos asistiendo a un momento de debilitamiento del Estado, por lo menos a nivel macro ${ }^{14}$. Mi pregunta es qué pasa si contrastamos ese supuesto debilitamiento, por ejemplo, con otros escenarios de fortalecimiento de ese mismo poder estatal, como es el caso de los poderes locales en las municipalidades. Me refiero especificamente a Chile porque es lo que conozco, pero me parece que no se ha medido el rol de la municipalidad como articulador de la gestión del Estado, principalmente en la relación con los estratos socioeconómicos más débiles, que justamente son los que más dependen de los beneficios o asistencias que entregan esas municipalidades. No sé si usted ve en esta dimensión una entrada para cuestionar, de alguna manera, este supuesto debilitamiento del Estado.

AK: La constatación de un debilitamiento del Estado es, obviamente, una generalización muy amplia que debe matizarse en el análisis de cada caso. El que mejor conozco es México, en donde sí ha habido una disminución o adelgazamiento del Estado en cuanto a su gasto, a la inversión pública, e incluso respecto de su mismo poder. Probablemente el Estado mexicano todavía es más fuerte que varios otros Estados, hablando muy abstractamente. Pero ha habido un cambio - justamente pensando en la cuestión que mencionas de los municipios-; ha habido un proceso de cierta devolución de poder y de gasto público, del Estado

${ }^{14}$ Conferencia magistral de Alan Knight "El Estado en América Latina desde la Independencia", dictada con ocasión de la inauguración del Centro de Estudios de Historia Política de la Universidad Adolfo Ibáñez (martes 25 de septiembre de 2012). 
central a los estados y a los municipios. Volvemos acá a lo que conversábamos al inicio, la existencia de al menos tres niveles de poder: el Estado central, los estados y los municipios.

Como historiador, es interesante esta pregunta porque me hace pensar un poco en un horizonte de más largo plazo. Por ejemplo, en los años veinte se produjo en México una suerte de balance -incluso en el gasto público- entre el poder central y el de los gobernadores que fueron figuras especialmente fuertes en esa década: Adalberto Tejeda en Veracruz y Lázaro Cárdenas en Michoacán. Por el lado opuesto, se ve en los setenta, durante los gobiernos de Luis Echeverría y José López Portillo, el período de mayor centralización fiscal y política, con una excesiva estatización de la economía, relacionada con el segundo auge petrolero que se produjo en esa década. Cuando este se desplomó, desencadenando la crisis de la deuda en 1982, comenzó este proceso de parcial debilitamiento del Estado central. Este proceso fue bienvenido por mucha gente, que lo consideraba como algo positivo en la medida que el Estado mexicano era visto como el "ogro filantrópico", el Leviatán, en contraste con una visión positiva sobre los poderes estatales y locales que serían en cambio más democráticos, al ser, supuestamente, más cercanos al pueblo ${ }^{15}$. En ciertos casos quizás haya algo de verdad en esto, como en el caso de algunos movimientos populares y cívicos en ciertos estados que pudieron de hecho afirmar un poco más su poder al producirse este debilitamiento del Estado central.

Ahora bien, el problema de todo esto, especialmente el caso de los municipios en México - que quizás no tenga nada que ver con Chile, ya que no conozco muy bien su realidad actual-, es que la devolución de poder al nivel local depende mucho de qué y quién constituye ese poder local, esto es, quién controla el municipio. Hay municipios que hoy son completamente controlados por los narcos y por los carteles; hay otros en donde hay caciques al antiguo estilo, como en Oaxaca por ejemplo; hay regiones en donde se ha devuelto el poder a las autoridades tradicionales indígenas, algo que también suena muy progresista y muy bonito. El problema, no obstante, es que, por ejemplo, al sostenerse en un sistema de usos y costumbres, a la manera de las

${ }^{15}$ La figura del ogro filantrópico refiere a la obra de Octavio Paz, El Ogro Filantrópico: Historia y Política, 1971-1978 (Barcelona: Seix Barral, 1979). La imagen del Leviatán remite, a su vez, a la obra de Thomas Hobbes, Leviatán: O la Materia, Forma y Poder de una República Eclesiástica y Civil (Madrid: Alianza, 1999), publicado por primera vez en 1651. 
comunidades indígenas tradicionales, no hay partidos, no hay elecciones normales y periódicas, y la ley central tiene una aplicación parcial y antojadiza. Hay tradiciones también muy machistas, que se establecen como prácticas en estos municipios legitimadas por la ley de la costumbre y oculta para el Estado que se ha debilitado.

Entonces creo que hay también un problema en la devolución de poder al municipio, que depende mucho de la naturaleza del municipio y de sus autoridades. Puede verse como algo democrático, progresista, pero en muchos casos esa devolución no necesariamente es tan positiva, e incluso puede fortalecer la autoridad de caciques locales y grupos como los narcos, que nada tienen de democráticos ni progresistas. Por lo tanto, es un problema y un desafío, para el que, sin embargo, no tengo una respuesta; soy historiador, y no es mi tarea buscar soluciones.

Pregunta: A mediados de los noventa usted abordaba el tema del populismo como una herramienta que circulaba y que se estaba procesando intelectualmente a propósito del nuevo escenario tras la caída del Muro de Berlín. La pregunta es si usted considera que el término tiene todavía algún rendimiento interesante para el análisis histórico de América Latina. ¿Está básicamente todo dicho en ese ámbito? Y, por otra parte, ¿usted visualiza cuáles son las áreas de extensión interesantes del término?

AK: En cuanto a mi perspectiva, he desarrollado ya todo lo que pienso sobre el tema y por tanto no tengo mucho más que decir sobre el populismo ${ }^{16}$. Hay gente, en cambio, que sigue trabajando sobre ese problema, incluso con el concepto de neopopulismo. En esa línea está, por ejemplo, Kurt Weyland, que, junto a otros, ha armado su carrera con este tema y ha producido cosas interesantes ${ }^{17}$. Por tanto me pa-

${ }^{16} \mathrm{Su}$ artículo sobre populismo fue publicado en español en una compilación de estudios de Alan Knight sobre la historia política de América Latina: Alan Knight, Revolución, Democracia y Populismo en América Latina (Santiago: Colección América Latina, Centro de Estudios Bicentenario y Pontificia Universidad Católica de Chile, 2005).

${ }^{17}$ Los planteamientos de Kurt Weyland pueden revisarse en el ensayo "Clarifying a Contested Concept: Populismo in the Study of Latin American Politics," Comparative Politics, Vol. 34 (octubre 2001), pp. 1-22, y en uno de sus principales libros, The Politics of Market Reform in Fragile Democracies: Argentina, Brazil, Peru, and Venezuela (New Jersey: Princeton University Press, 2002). 
rece válido que se siga hablando de populismo, aunque mi opinión sigue siendo todavía la misma, y es que para mí el populismo refiere fundamentalmente a un estilo de hacer política. Es útil como categoría ya que en todos los países — no es ningún monopolio de América Latina, pues se ve en Europa y en Estados Unidos- hay movimientos y líderes populistas. Se pueden establecer ciertos criterios - a mi juicio un poco vagos - acerca de la naturaleza del populismo, que normalmente tienen que ver con la relación entre el líder o el grupo que encabeza el movimiento y el pueblo, que es un concepto también muy vago. También se asocia a menudo con el contexto, en la medida que los movimientos populistas más fuertes suelen ocurrir en momentos de crisis - por ejemplo, cuando los partidos políticos se encuentran desarticulados-, lo que, sin embargo, no es una ley sino más bien una tendencia, que se asocia con la aparición de ideologías de contestación y polarización, de un "nosotros" contra "ellos", que pueden ser judíos, extranjeros, etc.

Ahora, para mí, como dije, es un estilo de política $-\mathrm{y}$ esto no es un enfoque muy sofisticado-, definición que permite pensar en individuos y movimientos populistas. En el caso de México yo podría, sin mucha dificultad, clasificar muchos políticos y movimientos como populistas o no. Pero, más allá de eso, no me parece una clasificación que aporte demasiado, y en ningún estudio he visto que el populismo se pueda utilizar como el concepto organizador para entender todo un período. Hay gente que ha intentado hacer eso en el estudio de América Latina, llamando a toda una etapa como "período populista". Empero, a mi juicio, es un ejercicio que no sirve. Aunque me parece una etiqueta con cierta utilidad, al igual que muchas otras como "radical" o "intransigente", el populismo puede describir un estilo, pero no una etapa. Y un problema derivado de esta idea de "etapas", de división en períodos, es que ha habido populistas antes y después; han aparecido en países más industrializados como Brasil, y en países más agrarios como Cuba o Nicaragua, con Batista y Somoza respectivamente, que tienen muchos rasgos populistas. Entonces, para mí, no es un reflejo de una forma de economía ni de una era, que es lo que se intentó plantear a mi juicio en la definición más clásica del populismo. Sin embargo, ello no quita que otros estudiosos lo consideren un concepto central para explicar ciertos procesos. 
Pregunta: Mi pregunta quizás obligue a hablar sobre el presente, ya que tiene que ver con un informe que publicó el año 2009 la revista Forbes, que dio la vuelta al mundo estableciendo la tesis de que México era un Estado fallido. A usted, que ha hecho una historia donde el Estado es un elemento central del análisis, ¿qué le parece esta afirmación? ¿Tiene algún sentido? ¿Hasta qué punto, dado el problema del narcotráfico en el norte, de la corrupción, y de tantos otros temas que se han hablado sobre México, tendría sentido establecer una teoría de este tipo, o calificar derechamente a México como un Estado fallido?

AK: Uno podría preguntar cuáles son exactamente los criterios de un "Estado fallido", ya que hay Estados que han fracasado en ciertos aspectos o ciertas regiones, y no en otras, lo que obliga a precisar el problema. Pero tratando de contestar tu pregunta, se puede decir que el Estado mexicano es un Estado fallido en algunas regiones, porque hay lugares como Ciudad Juárez, por ejemplo, en donde el estado de derecho no existe, y no ha existido durante varios años. En otras partes, como la frontera, y algunos estados del norte, o las regiones productoras en el llamado "triángulo del oro" que incluyen a Sinaloa, Durango, Chihuahua, el Estado tiene una presencia, pero muy débil. El ejército puede entrar, quemar sembradíos de marihuana, pero después sale y la producción del narcotráfico empieza otra vez. Ahora, decir que por ello México es un "Estado fallido", me parece un poco exagerado, ya que hay también muchas otras regiones donde el Estado sí tiene una existencia efectiva. Puede ser una presencia a veces algo autoritaria, y por tanto no siempre tan bonita ni positiva, que implique la protección de los pobres o un estado de derecho, pero es igualmente una presencia. Una manera de entrar al problema es mirando las cifras de homicidios, como una idea de la falta de estado de derecho, en que hay regiones como Yucatán donde los números son como en Canadá, mientras hay otras que quedan fuera de la escala, como Ciudad Juárez. Por lo tanto la distinción no es sólo entre zonas con un Estado ausente o presente, sino también respecto de la misma presencia del Estado, corrupta o no, débil o no. De manera que la clasificación debiera ser más compleja, donde se introduzca al análisis no sólo el problema de que el Estado no tenga presencia efectiva, sino también aquel de que, cuando la tiene, es una existencia corrompida por los carteles o los narcos. 
Hay otros países en el mundo que tienen estas características, como el caso de Colombia en América Latina, lo que evidencia que México no es una realidad tan fuera de lo común. Actualmente, y volviendo sobre la figura de Enrique Peña Nieto, está la incógnita sobre qué va a hacer o qué puede hacer respecto de este problema, de tan difícil solución especialmente en el tema de la violencia. Cuando el PRI dominaba el país, puso en todas las plazas a sus aliados, estableciendo un sistema corrupto y autoritario, pero en el que, sin embargo, al ser de alguna manera los amos del sistema, se minimizó la violencia, aun cuando existía exportación de drogas y carteles. Ese sistema corrupto se sostuvo en un mecanismo que controló la violencia entonces, tanto entre los mismos carteles como entre ellos y el Estado. Por diversas razones, que tuvieron relación con el tema económico, pero también con el derrumbe del PRI, la entrada del Partido de Acción Nacional (PAN) al gobierno y la iniciativa del ex presidente Felipe Calderón hace seis años de usar al ejército en contra de los carteles, los antiguos pactos y tratados por "debajo de la mesa" que garantizaron un cierto control del Estado, fueron rotos. Y a causa de ello es que existe hoy una suerte de guerra darwiniana entre estos grupos. Me cuesta trabajo entonces ver cómo un nuevo presidente, aunque pertenezca al PRI, podría rearmar un sistema así hoy día.

Pregunta: Mi pregunta tiene que ver con la discusión sobre sus referentes teóricos, donde se habló de Max Weber y Barrington Moore. ¿Cuáles serían sus interlocutores latinoamericanos, ya sean de la historiografía o de las ciencias sociales, en la reflexión sobre México? ¿Con qué autores está dialogando en el contexto latinoamericano?

AK: Hay muchos historiadores buenos en México, un país que siempre ha tenido una fuerte tradición historiográfica, quizás más creciente aún en las últimas décadas. Esto se puede ver en las librerías, en las bibliotecas, en las revistas que circulan, como Historia Mexicana y muchas otras. Ligado a la cuestión del regionalismo y el localismo en México, hay también un gran número de universidades, colegios y centros de investigación dedicados a estudiar la historia mexicana, que han minimizado la tan alta centralización de otros tiempos. Hoy puedes ir al norte, al sur, al centro, y encontrar en cada lugar diversos focos de investigación, lo que permite que existan muchos diálogos y muy buenos 
historiadores. Mencioné uno anteriormente, Luis González, quien murió hace poco, y que entre muchas otras obras escribió un libro llamado Pueblo en Vilo. Microhistoria de San José de Gracia, siendo con él el gran pionero del enfoque ${ }^{18}$. Este libro salió en 1968 y, aunque para mí nunca ha sido superado por otro historiador, ha habido un sinnúmero de estos estudios locales y regionales posteriores que han seguido su perspectiva, y que han sido fundamentales, al menos para mí, que estoy más bien del lado de la historia nacional.

Hay además en México una tradición de debate bastante fuerte, pienso que incluso más fuerte que en Estados Unidos, donde a veces hay un cierto temor al debate robusto y abierto. No sé si estarán de acuerdo conmigo en ese diagnóstico; yo al menos me estoy refiriendo específicamente al caso de los historiadores, no de los sociólogos o politólogos. Entonces existen en México muchas áreas de debate, en algunas de las cuales he podido participar y beneficiarme de los comentarios. Yo no sé si hay una sola persona que sea para mí un referente, aunque Luis González sea probablemente para mí el historiador que más ha influenciado a la generación de historiadores de México, yo incluido. Ahora, en términos teóricos hay que recordar el impacto de corrientes de interpretación que se han desarrollado en América Latina, como por ejemplo la Teoría de la Dependencia. Aunque para el día de hoy ya ha sido relativamente descartada - como dice Steve Haber, nada más valdría ponerla en la basura-, toda esta teoría, desarrollada por grandes intelectuales latinoamericanos como Fernando Henrique Cardoso y Enzo Faletto, fue un aporte fundamental que no ha perdido todo su valor.

Hay otros intelectuales que quisiera mencionar, como José Carlos Mariátegui, que escribió un buen ensayo sobre la Revolución Mexicana, ejemplo con el cual quiero evitar la impresión de que sólo fueron intelectuales del norte como Barrington Moore, o alemanes como Max Weber, los que me han influenciado. Pienso que el historiador puede ser bastante ecléctico; creo que es mejor leer por todos lados, beneficiándose incluso de Lyotard $\mathrm{u}$ otros que pueden ofrecernos una perspectiva interesante. Lo importante es reconocer dónde cada autor puede ser útil o valioso. El historiador, a mi juicio, se enfoca en pie $\mathrm{N}^{\circ} 7$.

${ }^{18}$ La referencia completa del texto de González se indicó en la nota al 
problemas bastante concretos: un país, una región, una comunidad, que se transforman en una problemática que puede ser abordada desde múltiples ideas, enfoques y autores, ya sea de Marx, de Weber, de Barrington Moore o cualquier otro teórico, historiador o antropólogo. Valga decir aquí la importancia que creo tienen los antropólogos, en especial Eric Wolf, al menos para mí, quien fue un gran ejemplo de vinculación entre antropología e historia, con lo que formuló interpretaciones sobre América Latina y el mundo muy fértiles.

Pregunta: Me gustaría volver a la idea de hacer una historia que comienza con conceptos analíticos. Y quiero plantear para ello un contraste de imágenes. Tenemos dos países cuyas revueltas y desorden comienzan con un problema electoral. Tenemos dos países donde hubo, en uno, una transformación mucho más grande del modo de producción que en el otro. $Y$, sin embargo, a pesar de estar cercanos en el tiempo, cercanos en el espacio geográfico, al conflicto del primero le llamamos "guerra civil" y al otro le llamamos "revolución". Estoy hablando, por supuesto, de la Guerra Civil de Estados Unidos y la Revolución Mexicana. ¿Por qué esta diferencia, que afecta la manera en que uno ve la historia norteamericana y la historia mexicana? Porque en el fondo la transformación social norteamericana, e incluso política, aunque muy tardía -y también la frustración, como en México-de los ideales que motivaron a los abolicionistas, pareciera que fueron mucho más profundas en Estados Unidos que en México. Y, sin embargo, nos mantenemos con la idea de que en una parte hubo una guerra civil y en la otra parte hubo una revolución.

Lo curioso, además, es que en la historiografia norteamericana se usa la palabra "revolución" para hablar de algo que no cambió nada, que es la Independencia, fuera de crear una estructura política centrada en un presidente. Entonces, ahí uno se da cuenta de cuáles son los sesgos analiticos que se producen en una historia cuando uno adopta dos conceptos que nadie cuestiona y que los reproduce mecánicamente. Porque si uno hace una historia de Estados Unidos basada en la idea de la guerra civil, como se ha hecho muchas veces, el tema es el de la autonomía de los estados, el tema es el hecho de que había un ejército enfrentado con otro, de dos estados, y no el despelote mexicano, donde había movimientos y procesos distintos. Pero si uno lo 
enfoca desde el punto de vista afroamericano, como lo hace la nueva historiografía sobre el tema, el resultado es completamente distinto, y la Revolución de Zapata no parece nada en comparación con la manera en que los ex esclavos se armaron, participaron en la guerra y se unieron a las tropas de la Federación. Con toda la enorme frustración que significó todo ese proceso para ese pueblo.

AK: Es cierto que el uso de "guerra civil" por un lado y "revolución” por otro es, en términos semánticos, muy importante. Y para nada más dar otro ejemplo, ha habido un sinnúmero de congresos y talleres de investigación sobre la independencia de América Latina en los últimos años para discutir justamente ese concepto. Me llama la atención en el caso de México — quizás para otros casos también- que hay una corriente de interpretación que quiere referirse a la Independencia de hace dos siglos como una guerra civil. Eso, en parte, es una manera de disminuir el significado del conflicto. Podemos debatir qué tan sustancial puede ser una "revolución" respecto a su transformación social o política exitosa, pero obviamente "revolución" es diferente de "guerra civil", así como ha habido muchas guerras civiles que en ningún caso fueron revoluciones. Inglaterra, por ejemplo, con las Guerras de las Rosas en el período medieval, vivió una guerra civil bastante sangrienta pero que no fue revolucionaria, en la medida que tenía que ver con grupos o facciones rivales. En la historia de América Latina conocemos también muchos casos de guerras civiles que no fueron o, más bien, no tuvieron ningún ímpetu o contenido revolucionario.

Me parece, entonces, que es una discusión importante. Supongo que en el caso de la Guerra Civil norteamericana, la idea de la guerra civil, que es la costumbre, es una manera quizás de disminuir lo que tú apuntas correctamente, y que es el cambio que significó la movilización popular de los negros y el hecho de que el sur quisiera emanciparse. Es importante además constatar que después de la revolución y de la reconstrucción, hubo también una contrarrevolución, ejemplificada en las leyes de Jim Crow, lo que, sin embargo, no niega en ningún caso el que haya sido un momento revolucionario. Barrington Moore sí refiere a la Guerra Civil norteamericana como una forma de revolución y puede ser que tenga razón. Supongo que esto tiene que ver un poco, en parte, con la autoimagen de los Estados Unidos como un país en donde las cosas son más o menos estables, donde hay consensos, y donde los 
movimientos revolucionarios y radicales están muy al margen. Al ser la Guerra Civil un gran problema, esta es quizás una manera de suavizarlo, dejando de lado su dimensión revolucionaria.

Ahora, si uno toma en cuenta toda la trayectoria, comparando lo que pasó en Morelos, con Emiliano Zapata, con lo que ocurrió en Estados Unidos o en el sur, no me parece que el primero haya sido menos importante. En Morelos se destruyó casi completamente la elite terrateniente, las plantaciones azucareras nunca se recuperaron, y hubo una reforma agraria muy amplia antes incluso de la llegada de Cárdenas. Claro, Morelos constituye el caso ejemplar de una revolución popular que conllevó rápidamente un cambio muy sustancial, no solamente en la tenencia de la tierra sino también en el gobierno, en donde hubo representantes campesinos ya en los años veinte. Hay otras partes de México, como Oaxaca, en donde los cambios fueron mucho más ligeros y menos importantes, que podrían ponerse en comparación con la Guerra Civil en Estados Unidos. Otra vez estamos en el problema de la diferencia regional.

Réplica: A lo que voy es que si uno usa la palabra "revolución", entonces uno se enfoca justamente en Zapata. Pero si hablas de "guerra civil", entonces te enfocas en otras cosas. Y esa es la importancia de siempre tener muy claro el efecto que tiene la manera en que uno investiga las cosas, de las categorías analíticas que emplea.

Pregunta: Yo siempre me he preguntado cuán útil es hacer una diferenciación conceptual tan rígida entre "revolución" y "guerra civil". Porque la verdad es que las revoluciones más importantes han tenido fuertes elementos de guerra civil. La francesa, la rusa, como revoluciones, han tenido también elementos de guerra civil. Entonces no sé qué tan útil sea optar muy monolíticamente por una u otra.

AK: Yo diría que toda revolución es una guerra civil, por definición. Pero revolución incluye además otras cosas, como una polarización ideológica — puede ser de clases, de regiones-, donde hay cuestiones muy importantes en juego. Podríamos agregar también aquí la cuestión de las revoluciones nacionalistas que, aplicada al caso de Estados Unidos, permitiría decir que la Guerra Civil fue una revolución nacionalista por parte del sur, que fue aniquilada por el norte. Esa es 
otra perspectiva comparativa interesante. Estoy de acuerdo, entonces, en que es necesario distinguir entre los dos, precisando eso sí que aunque toda revolución, por definición, es también una guerra civil, no toda guerra civil es revolucionaria. Ejemplo de ello es la Guerra de las Rosas en Inglaterra, que ya mencioné, el caso de la guerra de Nigeria en los años sesenta, donde se enfrentó el Biafra con el gobierno central, en los cuales los movimientos secesionistas y muchos otros que son guerras civiles, muy importantes y sangrientas, no son revoluciones, en el sentido de que no contienen dos programas, dos fuerzas, dos imaginarios colectivos en juego.

Pregunta: Me quedé pensando en lo que has mencionado al final de la charla acerca del legado de la Revolución Mexicana en la política actual de México. Y, sin ánimo de entrar a la cuestión de la teoría acerca de las revoluciones, creo que al analizar las revoluciones del pasado, de los últimos tres o cuatro siglos, uno encuentra ejemplos clásicos de revoluciones que se podrían dividir en dos grupos. El primero, por llamarlo de alguna manera, el de las revoluciones restituyentes, pensando en la de Gran Bretaña en 1688 y Francia en 1830. El segundo grupo sería el de las regenerativas, donde entrarían las más comunes o clásicas: Francia en 1789, Rusia en 1917 y me parece que, claramente en ese sentido, México quedaría entre esas. Sin embargo, tu último comentario me dejó pensando ¿hasta qué punto la resonancia actual de esa revolución es tan profunda o tan poderosa como en el caso de estas otras que mencioné, en sus países o en general?

AK: Como mencioné, probablemente semejante a lo que ha ocurrido con la Revolución Francesa, que ha tenido más de dos siglos de reflexión, con gente a favor y en contra, la Revolución Mexicana sí tiene una presencia en la política y hay gente que de vez en cuando la invoca, aunque yo diría que cada vez menos. Además, en México siempre hubo quienes rechazaron la Revolución, tomando en cuenta la existencia de un fuerte núcleo de católicos políticos que ha tenido una larga historia de oposición. De manera que la Revolución nunca fue, o nunca tuvo, el monopolio de la adhesión de todos los mexicanos. Siempre hubo bastante disidencia y cuestionamiento, principalmente desde los católicos pero también de otros grupos. 
Entonces, yo diría que hay una tradición, como en Francia, tanto de invocar la Revolución como de criticarla. Ahí tenemos, por ejemplo, a los zapatistas o al partido izquierdista en México, el Partido de la Revolución Democrática (PRD), que en cierta medida invocan a la Revolución. Su ex líder, Cuauhtémoc Cárdenas, es además hijo de Lázaro Cárdenas, por lo que también hay un aspecto familiar o dinástico que explica ese vínculo. Pero no sé bien en qué medida esta referencia histórica significa algo en la práctica. No quiero decir que no tiene nada que ver con la política contemporánea, pero creo que en México, como en muchos países, la política, las elecciones, los resultados tienen mucha más relación con la economía, el desempleo, la falta de seguridad del estado de derecho, la criminalidad, el acceso a la educación, etc. Entonces, la gente puede apelar a Cárdenas, en pro o en contra, pero no me parece que sea algo tan fuerte. Entre intelectuales está también este debate, que se discute en términos de los méritos o falta de méritos de la Revolución, que al final alude a lo mismo. Sin embargo, la Revolución es algo que pasó hace más de un siglo, lo que hace de ella más que nada una referencia histórico-cultural, pero no un factor que incida directamente en los tiempos actuales. Hoy estamos a tres o cuatro generaciones de la Revolución, ya no quedan los que lucharon, quizás sólo queden algunos ya muy ancianos, por lo que es un hecho ya muy lejano.

Hay debates interesantes en la historiografía, y no sólo entre los académicos sino también, por ejemplo, en los libros de texto. En los años noventa hubo un esfuerzo para reescribir todos los libros de texto, sacando a los supuestos "buenos" como Lázaro Cárdenas o Emiliano Zapata —o el episodio de los niños héroes que se arrojaron del castillo de Chapultepec para no rendirse a los norteamericanos, en la guerra de 1847- para reescribirlos con nuevos enfoques, nuevos héroes, nuevos villanos. Incluso se incorporó una suerte de revalorización de la figura de Porfirio Díaz, algo muy interesante que no sólo se dio en el espacio de los libros de texto sino en las telenovelas, donde se ha mostrado a Díaz como una persona mucho más heroica, que contribuyó al crecimiento de la economía y la estabilidad mexicana. A fin de cuentas, los libros de texto fueron un fracaso, tuvieron mucha oposición, en parte debido al rechazo por parte del sindicato de maestros — quizás por razones ideológicas, quizás por razones puramente personalistas y políticas-- de manera que no se dio paso a una nueva generación de libros de texto más radical, o más neoliberal. Este es entonces un ejemplo 
donde sigue operando la influencia de la Revolución, que me parece que de vez en cuando vuelve a entrar en la política contemporánea, aunque, insisto, lo hace cada vez menos.

Pregunta: Mi pregunta es cómo conciliar la definición que usted hace de la Revolución Mexicana como, efectivamente, una revolución, $y$ el hecho de que los zapatistas hayan sido derrotados, siendo justamente los elementos más radicales del bando revolucionario. Al ser asesinado Zapata, lo que se implementó en Morelos no se implementó en el resto de México, lo que permite ver en eso la derrota del zapatismo. Limitándose entonces, en ese sentido, a Morelos, ¿podría hablarse de una Revolución Morelense y no de una Revolución Mexicana?

AK: No sé qué quieres decir exactamente con la idea de que el zapatismo fue derrotado. Sí comparto que fue una Revolución, y que el zapatismo fue el movimiento más consistente y más fuerte, pero no me parece tan cierto que haya sido derrotado. Es cierto que Zapata fue asesinado, pero los movimientos pueden seguir una vez que asesinan al líder, y eso fue lo que pasó en Morelos. Y no se extrapoló lo que ahí se llevó a cabo, en parte, porque fue un movimiento fundamentalmente local, un movimiento muy regionalista, lo que constituyó una de sus fuerzas y también de sus debilidades. Podría entonces plantearse lo que tú señalas, la idea de una Revolución Morelense, pero habría que agregar que no fue una sola; hubo otras revoluciones, quizás menos radicales, en otras partes. Si uno piensa en el cardenismo en Michoacán, el tejedismo en Veracruz, es posible reconocer la existencia de otros movimientos revolucionarios. Claro que hay diferencias entre ellos, pero es importante constatar que hubo diversos movimientos: de protesta, de modernización — militar y política—, de una reforma agraria, de expansión de la educación federal, formación de sindicatos potentes, etc. La reforma agraria fue quizás lo más nuevo, porque bajo Porfirio Díaz hubo una verdadera concentración de las tierras. Con la Revolución, el giro fue de 180 grados, porque se distribuyeron esas tierras a los campesinos. La educación federal había comenzado, en parte, con Díaz, pero la Revolución la hizo más amplia y mucho más rural, con todo un cuadro de maestros que se desplazaron por el país - y que no son los maestros actuales, sino con una formación diferente que tenía que ver con una misión social-. 
Entonces, no es simplemente una Revolución Morelense, había más revoluciones, o mejor dicho, muchas experiencias durante la Revolución que se podrían calificar como revolucionarias. Y como historiador, intentando armar un conjunto a partir de estas experiencias diversas, me parece que es posible plantear que fueron suficientemente importantes respecto a los cambios que provocaron para definirlas en su unidad como una Revolución. Si uno quiere decir "no", porque necesitas a Stalin, la colectivización, la formación de una economía planeada para reconocer una verdadera revolución, está bien; al final, es una cuestión de criterios. Sin embargo, a mi juicio, si la Revolución Mexicana no fue una revolución, me cuesta trabajo ver cuáles otras sí lo serían. La Francesa en cierto sentido, pero en otros no; la Boliviana, para nada, y así.

Regresando a la cuestión del zapatismo, es cierto que fue limitado y regional, por lo que es cierto también lo que afirmas de que el éxito del zapatismo no quiere decir el éxito de la Revolución. Y de hecho, sumando las demás experiencias - y hay excepciones, Yucatán, Oaxaca-, la Revolución fue mucho más débil que lo que pasó específicamente en Morelos. No obstante, creo, fueron ejemplos y experiencias suficientes para considerarlos como parte de una revolución.

Pregunta: Con la perspectiva del tiempo, da la sensación de que la Revolución Mexicana, pese a su extensión temporal y a la fuerza que alcanzó, no tuvo el mismo potencial para transformarse en un modelo de cambio en otros países -incluso latinoamericanos-que el que tuvieron otras revoluciones más adelante, como la cubana o la rusa. ¿A qué se debería eso? ¿Será porque no había una ideología universalista detrás? ¿O habrá otros elementos?

AK: Los líderes mexicanos no fueron muy dedicados a exportar la Revolución. En este sentido, son diferentes a los franceses o los rusos, para los que, aunque de manera muy diferente, fue clave difundir su idea de revolución, así como su experiencia. No así para los mexicanos, en parte por temor a Estados Unidos. Enfaticé antes que Estados Unidos no se involucró demasiado - o con éxito - en el proceso revolucionario en México, pero ello fue también, en parte, porque los mexicanos no querían molestar demasiado al "coloso del Norte". Hubo momentos en los años veinte, cuando México tuvo relaciones con los 
liberales en Nicaragua, con Augusto César Sandino y otros, apoyándolos en sus objetivos, entregándoles armas, etc., en que Estados Unidos reaccionó. Se generó todo un conflicto diplomático que terminó, más o menos, con el retiro de Calles, y no lo plantearía como una traición para Sandino, pero el apoyo mexicano efectivamente se desvaneció. Y sabemos qué pasó después con Sandino. Entonces nunca hubo un esfuerzo muy concreto por exportar la Revolución. En parte también porque los mexicanos siempre han enfatizado que la Revolución es $s u$ revolución, es distinta, no una revolución comunista o de cualquier otro tipo. Siempre ha habido un énfasis en eso: esta fue una revolución nacionalista. No hemos hablado mucho de eso, pero sí es una dimensión importante, que explica el hecho de que no haya sido exportada a otros países.

Hubo algunas influencias sin duda, que se ven por ejemplo con la formación de la Alianza Popular Revolucionaria Americana (APRA) en Perú y la figura de Raúl Haya de la Torre, que había estado en México algún tiempo. Y la influencia se puede observar en cierta semejanza que existió entre el programa del APRA y la Revolución Mexicana. Para conocer mejor esta influencia habría que conocer mejor también la historia de otros países, como el Perú, pero esa no es mi propia expertise. Aun así, me parece que las influencias son visibles no sólo en el caso del APRA, sino en Cuba y en Centroamérica, pero no debido tanto a una política de exportación de los propios mexicanos, sino a la existencia de ciertas referencias. Ejemplo de ello es el caso de los bolivianos y el Movimiento Nacionalista Revolucionario (MNR) de los años cincuenta, que hicieron referencia a la reforma agraria mexicana como un modelo válido a seguir. Sin embargo, si la Revolución Mexicana nunca hubiera existido, quizás los bolivianos habrían hecho más o menos lo mismo. ¿Quién podría decirlo? 